\title{
Winning images from the Art in Science and Engineering in Medicine (ARSENIC) competition
}

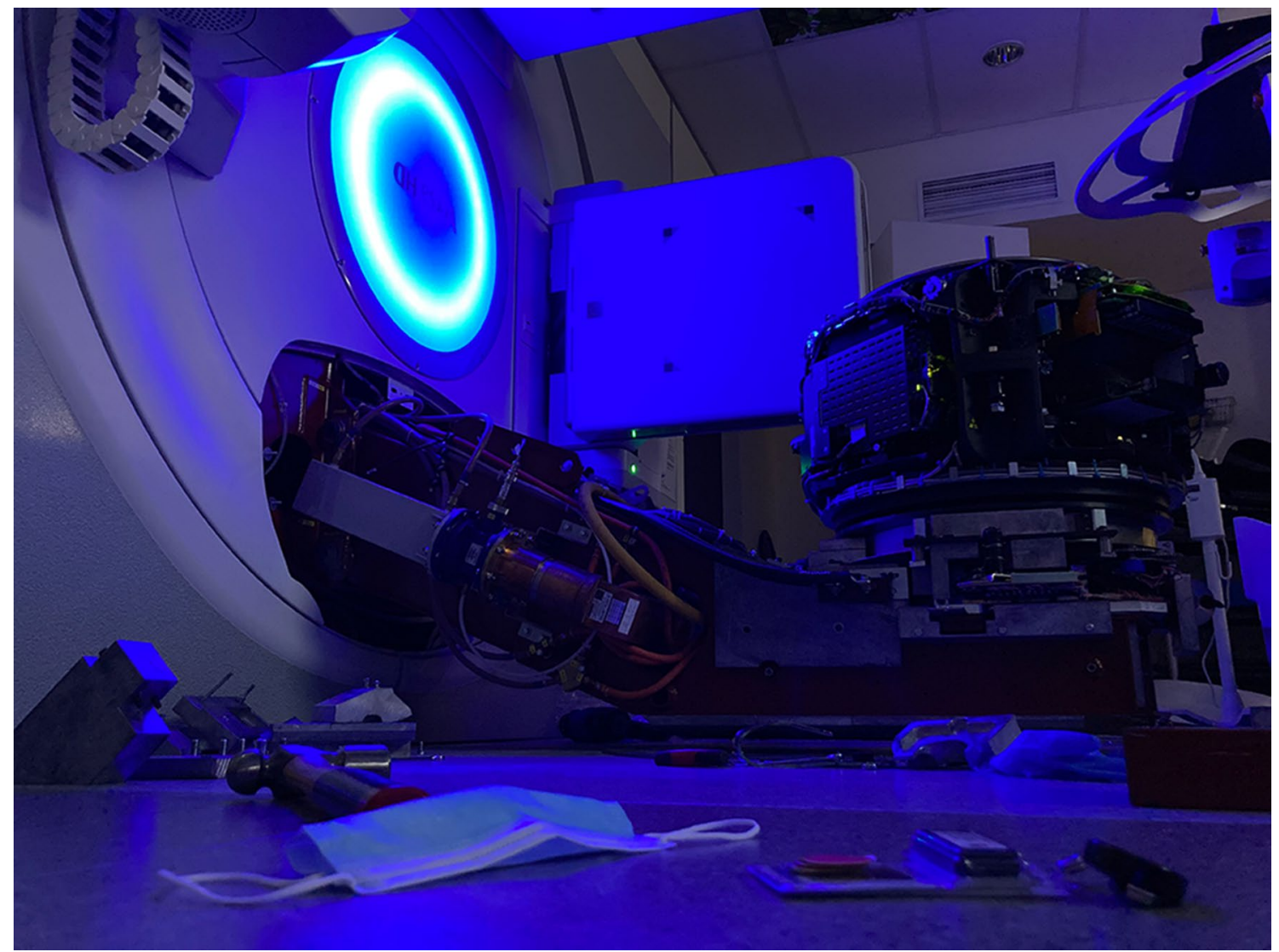

Winning images from the Art in Science and Engineering in Medicine (ARSENIC) competition https://photograph yinmedicalphysics.com.

Winners are judged by a jury of professionals from Medical Physics and Photography for the Professional Judging category, and by public voting for the People's Choice category.

Publisher's Note Springer Nature remains neutral with regard to jurisdictional claims in published maps and institutional affiliations. 